PUBLIC HEALTH RESEARCH

\title{
Alcohol Consumption Practices Among Nepali Migrant Workers in Shah Alam, Selangor
}

\author{
Hasanain Faisal Ghazi, ${ }^{1,2 *}$ Mohammed A. AbdalQader, ${ }^{2}$ Mohammed Faez Baobaid, ${ }^{2}$ Indang Ariati Ariffin, ${ }^{2}$ \\ Mariam-Aisha Fatima, ${ }^{3}$ Afrisya Adlina Mohd Azhar, ${ }^{2}$ Muhammad Mukhlis Ma'arof, ${ }^{2}$ Tiba Nezar Hasan 4 and \\ Mohd Rohaizat Hassan
}

${ }^{1}$ College of nursing, Al-Bayan University, Baghdad, Iraq.

${ }^{2}$ International Medical School, Management \& Science University, Selangor, Malaysia.

${ }^{3}$ Research Management Centre, Management \& Science University, Malaysia.

${ }^{4}$ Department of Dentistry, Al-Turath University College, Baghdad, Iraq.

${ }^{5}$ Department of Community Health, UKM Medical Centre, Kuala Lumpur, Malaysia.

*For reprint and all correspondence: Assoc. Prof. Dr. Hasanain Faisal Ghazi, College of Nursing, Al-Bayan University, Baghdad, Iraq.

Email: dr.hasanainhabasha@gmail.com

\section{ABSTRACT}

\begin{tabular}{ll}
\hline Introduction & Malaysia has been considered an industrialized country and there is a demand \\
& for manpower in low-skilled jobs which usually filled by migrant workers. \\
& Therefore, this study focused to identify the level of alcohol consumption and \\
its associated factors among Nepali migrant workers in Shah Alam, Selangor. \\
A cross-sectional study using a convenient sampling method was conducted \\
among 233 Nepali migrant workers in Shah Alam, Selangor using a self- \\
administered questionnaire. A validated questionnaire (The Alcohol Use \\
Disorder Identification Test) by WHO was used in the study. \\
The results showed that $60.09 \%$ of Nepali workers consumed alcohol with \\
most of them are in low (31.43\%) and medium (29.28\%) risk level for alcohol \\
consumption. The empirical findings revealed a significant association \\
between income, education level, and peer pressure with alcohol consumption \\
(p value <0.001 respectively). However, the study found no association \\
between age, marital status, years of working, and body mass index with \\
alcohol consumption (p value= 0.44, 0.19, 0.42, 0.40 respectively). \\
In conclusion, most Nepali migrant workers consumed alcohol but in low and \\
medium risk severity. The results highlighted socio-demographic factors such \\
as income and education as well as peer pressure among the important factors \\
affecting alcohol consumption. Thus, it is important to address this issue by \\
creating awareness by conducting health talk and campaign. This can give a \\
clear idea to migrant workers on the health effect of alcohol consumption. \\
More education and promotion are needed to address the health effect of \\
excessive alcohol consumption and work productivity among migrant workers \\
in their own language. \\
Working Conditions - Lifestyle - Alcohol Consumption - Nepali Migrant \\
Worker - Selangor.
\end{tabular}

Article history

Received: 5 March 2021

Accepted: 15 June 2021

Published: 1 September 2021 


\section{INTRODUCTION}

Alcohol intake and harmful use are substantial contributors to death and disease worldwide, posing a threat to both individual and social development. Around 11.5 percent of drinkers worldwide engage in weekly heavy episodic drinking, with men outnumbering women four to one. In all regions, men regularly engage in risky drinking at considerably higher rates than women. ${ }^{1}$

Malaysia is an industrialised country and underwent rapid development in multiple different sectors such as construction, manufacturing, and agriculture. Therefore, Malaysia is facing a need of manpower in low-skilled jobs which is usually filled by migrant workers. Hence, Malaysia hosts an increasing number of migrant workers. According to Nepal's Department of Foreign Employment (DoFE) in 10 years, 1,408,666 Nepalese migrant workers migrate to Malaysia. ${ }^{2}$ In spite of that, increasing number of migrant workers also creates problems.

Nowadays, there are cases related with alcohol consumption among migrant workers. A study done by Rathod et al. ${ }^{3}$ on prevalence and correlates of alcohol use in a central Nepal district reported that over half $(53.7 \%)$ out of 1,130 men respondents recently consumed alcohol. The harmful use of alcohol is stated to be the most leading factor for various non-communicable diseases (NCDs) such as cardiovascular diseases, liver cirrhosis and malignancy. ${ }^{4}$ Furthermore, according to $\mathrm{WHO},{ }^{1}$ there are 3 million deaths annually caused by alcohol abuse which contributes to $5.3 \%$ of all deaths worldwide. The global alcohol attributable deaths are more among male drinkers as compared to female drinkers. ${ }^{1}$

The health of migrants and health associated with migration are crucial public health challenges faced by governments and societies. Based on the study done by Rock et al., ${ }^{5}$ it shows that among the migrant workers, $40(19 \%)$ were screened positive for mental health problems and 45 (21\%) consumed alcohol. A total of $4 \%, 2 \%$ and $1 \%$ of them were abusing, suffering from withdrawal, and suffering from dependence of alcohol. Psychological factor including stress can lead to alcohol consumption among migrant worker. Besides, we also need to measure the correlation between stress level and how much alcohol was consumed by migrant workers.

A previous study done in a central Nepal district showed an association between alcohol consumption and age range between 30 to 39 years old. ${ }^{3}$ A study on alcohol consumption among immigrant Latino farm workers showed that heavy consumption was more common among individuals with a secondary education or higher. ${ }^{6}$ The lowest income group are the most likely to drink which acquired $52.4 \%$ of male respondents. ${ }^{3}$

This study aims to identify the level of alcohol consumption and its associated factors among Nepali migrant workers in Shah Alam, Selangor.

\section{METHODS}

This cross-sectional study was conducted in Selangor among 233 Nepali migrant workers by using a non-probability convenient sampling method. The inclusion criteria were Nepali working in Selangor, male aged more than 18 years old and those who were willing to participate. The exclusion criteria were those with mental disability.

An interview technique was used to collect the data. The questionnaires consist of part A which is about socio-demography such as age, income, educational level and marital status. Part B is about working environment, part $\mathrm{C}$ is regarding stress level, part $\mathrm{D}$ is about lifestyle factors, part $\mathrm{E}$ is about body mass index, and part $\mathrm{F}$ is regarding alcohol consumption.

The scoring system used for alcohol consumption is The Alcohol Use Disorder Identification Test by $\mathrm{WHO}^{7}$ which consist of 10 questions with a cut-off point for respective severity. ${ }^{8}$ Those who scored $0-7$ were considered as low risk while those who scored 8-15 were categorized under medium risk. In addition, those who scored 16-19 were considered as high risk and those who scored 20-14 were considered as addiction.

Ethical approval was obtained from MSU ethics committee. Consent was taken from the participants before answering the questionnaire. Data were analysed by using JASP 0.11 .1 .0 software. Mean and standard deviation were used for numerical variables while frequency and percentage were used for categorical variables. Chi square test, fisher exact test, one-way ANOVA tests were used to test association between variables.

\section{RESULTS}

Table 1 shows respondents' marital status whereby majority of them were married 155 (66.52\%), followed by those who were single $71(30.47 \%)$ and divorced 7 (3.0\%). Based on education, majority of the respondents had secondary and university education with result of $124(53.22 \%)$ and 53 $(22.75 \%)$ respectively as shown in the Table 1.

Table 1 Sociodemographic factors among respondents

\begin{tabular}{lrrr}
\hline \multicolumn{2}{l}{ Socio-demographic factors } & N & \multicolumn{2}{c}{$\%$} \\
\hline Marital & Single & 71 & 30.47 \\
& Married & 155 & 66.53
\end{tabular}




\begin{tabular}{|c|c|c|c|c|c|}
\hline \multirow[b]{2}{*}{ Education } & \multirow{2}{*}{$\begin{array}{l}\text { Divorced } \\
\text { No education }\end{array}$} & \multicolumn{2}{|r|}{7} & \multicolumn{2}{|r|}{3.00} \\
\hline & & & 12 & & 5.15 \\
\hline \multirow{5}{*}{ Peer pressure } & Primary & & 44 & & 18.88 \\
\hline & Secondary & & 124 & & 53.22 \\
\hline & University & & 53 & & 22.75 \\
\hline & No & & 55 & & 37.93 \\
\hline & Yes & & 90 & & 62.07 \\
\hline \multicolumn{2}{|c|}{ Socio-demographic factors } & Min & Max & Mean & $\mathrm{SD}$ \\
\hline \multicolumn{2}{|c|}{ Age } & 20.00 & 52.00 & 31.93 & 6.45 \\
\hline \multicolumn{2}{|c|}{ Income (RM) } & 450.00 & 4500.00 & 1928.80 & 599.63 \\
\hline \multicolumn{2}{|c|}{ Body mass index $\left(\mathrm{kg} / \mathrm{m}^{2}\right)$} & 15.78 & 39.70 & 24.19 & 3.26 \\
\hline
\end{tabular}

Table 2 shows that 233 respondents, 140 $(60.09 \%)$ of the Nepali workers consumed alcohol and the remaining $93(39.91 \%)$ did not. There are four categories of the severity for alcohol consumption in which the majority were having low and medium risk. Meanwhile, 44 (31.44\%) were having low risk, 41 (29.28\%) were having medium risk, $28(20 \%)$ were having high risk and 27 $(19.28 \%)$ were having addiction. This result showed that 1 out of 5 Nepali workers had an addiction to alcohol.

Table 2 Alcohol consumption and alcohol severity among respondents

\begin{tabular}{llrl}
\hline & & $\mathrm{N}$ & $\%$ \\
\hline Alcohol consumption & No & 93 & 39.91 \\
& Yes & 140 & 60.09 \\
Alcohol severity & Low risk & 44 & 31.43 \\
& Medium risk & 41 & 29.28 \\
& High risk & 28 & 20.00 \\
& Addiction & 27 & 19.28 \\
\hline
\end{tabular}

Table 3 shows that majority of the respondents who were married, are categorized under low and medium risks both with equal percentage of 27 (30.68\%). Respondents who were single mainly falls under the low and medium risk group with the percentage of $16(34.04 \%)$ and 10 $(21.28 \%)$ respectively as shown in the Table 3.

Table 3 Association between alcohol consumption level and sociodemographic factors

\begin{tabular}{|c|c|c|c|c|c|c|c|}
\hline \multirow{2}{*}{\multicolumn{2}{|c|}{$\begin{array}{l}\text { Socio-demographic } \\
\text { factors }\end{array}$}} & \multirow[b]{2}{*}{$\begin{array}{l}\text { Low risk } \\
\mathrm{N}(\%)\end{array}$} & \multicolumn{2}{|c|}{ Alcohol severity } & \multirow[b]{2}{*}{$\begin{array}{l}\text { Addiction } \\
\text { N (\%) }\end{array}$} & \multirow[b]{2}{*}{$\mathrm{x}^{2}$} & \multirow[b]{2}{*}{ P-value } \\
\hline & & & $\begin{array}{l}\text { Medium risk } \\
\text { N (\%) }\end{array}$ & $\begin{array}{l}\text { High risk } \\
\text { N (\%) }\end{array}$ & & & \\
\hline \multirow[t]{6}{*}{ Marital } & Single & 16 & 10 & 12 & 9 & 8.70 & 0.190 \\
\hline & & $(34.04)$ & $(21.28)$ & $(25.53)$ & $(19.15)$ & & \\
\hline & Married & 27 & 27 & 16 & 18 & & \\
\hline & & $(30.68)$ & $(30.68)$ & (18.18) & $(20.45)$ & & \\
\hline & Divorced & 1 & 4 & 0 & 0 & & \\
\hline & & $(20.00)$ & $(80.00)$ & $(0.00)$ & $(0.00)$ & & \\
\hline \multirow[t]{8}{*}{ Education } & No & 1 & 4 & 1 & 1 & 26.69 & $<0.001$ \\
\hline & education & $(14.29)$ & $(57.14)$ & (14.29) & $(14.29)$ & & \\
\hline & Primary & 13 & 8 & 3 & 2 & & \\
\hline & & $(50.00)$ & $(30.77)$ & $(11.54)$ & (7.69) & & \\
\hline & Secondary & 28 & 22 & 14 & 11 & & \\
\hline & & $(37.33)$ & $(29.33)$ & $(18.67)$ & $(14.67)$ & & \\
\hline & University & 2 & 7 & 10 & 13 & & \\
\hline & & $(6.25)$ & $(21.88)$ & $(31.25)$ & $(40.63)$ & & \\
\hline
\end{tabular}

Fisher exact test was performed, level of significant at $P<0.05$

The majority of the respondents in secondary education falls under the low and medium risk level with percentage of $28(37.33 \%)$ and 22 $(29.33 \%)$ respectively, while those with university education mainly falls under the high risk and addiction level the percentage of $10(31.25 \%)$ and 13 $(40.63 \%)$ respectively as shown in Table 3 . This shows that those with tertiary education level were 
more prone to have alcohol addiction. Thus, our study shows that there was a significant association $(\mathrm{P}<0.001)$ between education and alcohol consumption.

For the association between alcohol consumption and age, the majority of respondents were having low risk with the mean age of 30.57 years old while the respondents with addiction were the least with the mean age of 31.48 years old (Table
3). However, there was no significant association between the two variables $(\mathrm{p}=0.440)$.

Based on our study on the association between alcohol consumption and income, majority of the respondents were having low risk with the mean income of RM 1,743.18 while the respondents with addiction were the least with the mean income of RM 2,296.30 as shown in Table 4. The association was significant wit $\mathrm{P}<0.001$.

Table 4 Association between alcohol consumption level and age, income and BMI

\begin{tabular}{llrrrr}
\hline $\begin{array}{c}\text { Socio-demographic } \\
\text { factors }\end{array}$ & Alcohol severity & N & Mean & SD & P value \\
\hline Age & Low risk & 44 & 30.57 & 6.15 & 0.440 \\
& Medium risk & 41 & 31.98 & 6.24 & \\
& High risk & 28 & 29.75 & 5.20 & \\
Income & Addiction & 27 & 31.48 & 6.33 & \\
& Low risk & 44 & 1743.18 & 375.65 & $<0.001$ \\
& Medium risk & 41 & 1936.10 & 722.91 & \\
BMI & High risk & 28 & 2078.57 & 602.07 & \\
& Addiction & 27 & 2296.30 & 565.33 & \\
& Low risk & 44 & 24.50 & 4.30 & 0.400 \\
& Medium risk & 41 & 23.46 & 2.80 & \\
& High risk & 28 & 24.29 & 2.77 & \\
\hline
\end{tabular}

ANOVA test was performed, significant level at $p<0.05$

Based on the association of alcohol consumption and BMI, majority of the respondents were having low risk while the lowest percentage was among the addiction group with the mean BMI of $24.50 \mathrm{~kg} / \mathrm{m} 2$ and $23.54 \mathrm{~kg} / \mathrm{m} 2$ respectively. However, the association was not significant with $\mathrm{p}=0.400$.

Table 5 shows that the majority of the respondents who were pressured to drink falls under the categories of medium risk and addiction with the frequency and percentage of $26(29.55 \%)$ and 25
$(28.41 \%)$ respectively. Meanwhile, majority who were not pressured to drink falls under the low risk group 28(53.85\%). There was a significant association between peer pressure and alcohol consumption level $(\mathrm{P}<0.001)$. Based on working shift, most of the respondents who were working in the morning and night shift fall under the low and medium risk categories as shown in Table 5 . However, the association was not significant $(\mathrm{P}=220)$.

Table 5 Association between PPER pressure, working shift and alcohol consumption level

\begin{tabular}{|c|c|c|c|c|c|c|c|}
\hline \multicolumn{2}{|c|}{ Working environment } & \multicolumn{4}{|c|}{ Alcohol severity } & \multirow[b]{2}{*}{$\mathrm{x}^{2}$} & \multirow[b]{2}{*}{$\begin{array}{l}\mathrm{P} \\
\text { value }\end{array}$} \\
\hline & & $\begin{array}{l}\text { Low risk } \\
\mathrm{N}(\%)\end{array}$ & $\begin{array}{c}\text { Medium risk } \\
\mathrm{N}(\%)\end{array}$ & $\begin{array}{l}\text { High risk } \\
\mathrm{N}(\%)\end{array}$ & $\begin{array}{l}\text { Addiction } \\
\mathrm{N}(\%)\end{array}$ & & \\
\hline \multirow[t]{4}{*}{ Peer pressure } & No & 28 & 15 & 7 & 2 & 25.23 & $<.001^{\mathrm{a}}$ \\
\hline & & $(53.85)$ & $(28.85)$ & $(13.46)$ & $(3.85)$ & & \\
\hline & Yes & 16 & 26 & 21 & 25 & & \\
\hline & & $(18.18)$ & $(29.55)$ & $(23.86)$ & $(28.41)$ & & \\
\hline \multirow{4}{*}{$\begin{array}{l}\text { Working } \\
\text { shift }\end{array}$} & Morning & 25 & 23 & 14 & 9 & 4.40 & $0.22^{\mathrm{a}}$ \\
\hline & & $(35.21)$ & (32.39) & (19.72) & $(12.68)$ & & \\
\hline & Night & 19 & 18 & 14 & 18 & & \\
\hline & & $(27.54)$ & $(26.09)$ & $(20.29)$ & $(26.09)$ & & \\
\hline
\end{tabular}

chi square test was performed, significant level at $p<0.05$

The result of association between working hours and alcohol consumption level showed that the majority of respondents with the mean working hour of 11.27hours fall under the low risk category while the number of respondents with addiction was the least with the mean working hour of 10.74 hours as shown in Table 4. The association however was not significant $(\mathrm{p}=190)$. 
The association between years of working in Malaysia and alcohol consumption in Table 6 showed that majority of the respondents with the mean years of working of 3.99 years falls under the low risk category while the number of respondents with addiction was the least with the mean years of working of 4.76 years. However, the association was not significant $(\mathrm{p}=190)$.

\section{DISCUSSION}

The main finding of the current study was $60.00 \%$ of the respondents consumed alcohol. Regarding the severity of consumption, there were four categories of severity and we can conclude that the majority of respondents were having low and medium risk. Meanwhile, (32.43\%) were having low risk, $(29.28 \%)$ were having medium risk, $(20.00 \%)$ were having high risk and (19.28\%) were having addiction. The outcome of this research is comparable with a previous study ${ }^{3}$ about alcohol consumption in central Nepal district which reported that over half $(53.7 \%)$ of men out of 1130 respondents consumed alcohol.

Alcohol consumption among migrant workers is a serious public health concern in several parts of the world. Heavy drinkers are more prone to major non-communicable diseases such as liver cirrhosis, cancer, and cardiovascular diseases and social problems such as driving under the influence and resultant injuries from road clashes and collisions. ${ }^{4,6}$ With the economic growth in Malaysia, this causes an increased demand in workforce for different sectors thus causing a high number of migrants travelling to Malaysia.

Based on the outcome of our research, married men were more likely to consume alcohol compared to single and divorced men. Our study showed that there was no association between alcohol consumption level and marital status. However, it shows that majority of Nepali migrant workers who consumed alcohol was married. Our findings are parallel with another study by Rathod et al. ${ }^{3}$ whereby despite the result was not significant, married individuals were the most likely to drink alcohol which comprised of $55.4 \%$ of the male Nepalese respondents.

In terms of education level, the majority of the respondents who consumed alcohol come from the secondary and tertiary education level. The findings of our study showed that there was a significant association between education and alcohol consumption level. Our research is supported by the study result on alcohol consumption among immigrant Latino farmworkers where heavy consumption was more common among individuals with a secondary education or higher. ${ }^{6}$ However, our result is in contrast with another study done by Rathod et al. ${ }^{3}$ which stated that highest amount of alcohol consumption was among the male respondents $(58.10 \%)$ who have completed only up to the primary educational level.

A previous study done on the prevalence and correlates of alcohol use in a central Nepal district showed an association between alcohol consumption and age where individuals who were that are most likely to drink were from the age range of 30 to 39 years old. ${ }^{3}$ However, results from our study showed that there was no significant association between age and alcohol consumption level. Our finding was supported by a 2001 national survey that showed $67.5 \%$ of the total samples within the age group of 15-59 years old have consumed alcohol. ${ }^{9}$

Based on the sociodemographic factors, it shows that majority of the respondents were at low risk of alcohol consumption. It also shows that the respondents in this category had the lowest income. Our findings showed no significant association between income and alcohol consumption level shows there is significant association. This corresponds with the previous study reporting that the lowest income group was the most likely to drink alcohol ${ }^{3}$ and a survey done by Blas et al. ${ }^{10}$ noted that low socioeconomic status can be a risk factor and consequence of alcohol consumption.

Results from our study showed that there was no significant association between body mass index and alcohol consumption level. This result contradicts with a study done by Fawehinmi et al. ${ }^{11}$ which found an association between alcohol consumption and BMI in female but not in male. Female moderate drinker has lower BMI compared to non-drinker and female heavy drinkers had a higher BMI than non and moderate drinkers. Another study done by Mejean et al. ${ }^{12}$ showed it shows that the effect of migration on overweight was mediated by alcohol consumption.

Our findings showed no significant association between peer pressure and alcohol consumption level shows there is significant association. This result is supported by a previous study in which young adults were more likely to smoke and drink if they believed most of their close friends have the same behavior as seen in the high odds ratios in the results. ${ }^{13}$ Another study done by Nguyen et al. ${ }^{13}$ stated that although the difference was not significant, males who live with friends or classmates tend to drink and smoke more than males who live with parents or spouses or children.

Our findings showed no significant association between working conditions (working shift, hours and years) and alcohol consumption level shows there is no significant association. This is supported by a study done by Azagba \& Sharaf ${ }^{14}$ which stated that the effect of job strain on alcohol consumption of adults in France showed that being immigrant and working with a medium job strain have a low probability for alcohol consumption. However, our research contradicts with a previous 
study which shows there was an association between long working hours and higher levels of alcohol use in a cross-sectional study of 333693 participants from 14 countries ${ }^{15}$. The limitation of our study that it was limited to one location in Malaysia and limited access to migrant workers. Future studies need to address other nationalities working in Malaysia and to include other states also.

\section{CONCLUSION}

In conclusion, the prevalence of alcohol consumption in this study was $60.00 \%$ whereby the majority were having low risk $(31.44 \%)$ and medium risk (29.28\%). Our study showed that there were associations between alcohol consumption level and income, education and peer pressure. Thus, more education and promotion are needed to address excessive alcohol consumption and work productivity and health among migrant workers in their own language.

\section{REFERENCES}

1. World Health Organisation. Global status report on alcohol and health. World Health Organization, 122(December 1994), 1-85. 2011. Available from https://apps.who.int/iris/bitstream/handle/1 0665/274603/9789241565639-

eng.pdf?ua $=1$.

2. Baruah N \& Arjal N. Nepalese Labor Migration: A Status Report - The Asia Foundation. InAsia. 1-10. 2018. Available from

https://asiafoundation.org/2018/06/06/nep alese-labor-migration-a-status-report/.

3. Rathod SD, Luitel NP \& Jordans MJD. Prevalence and correlates of alcohol use in a central Nepal district: secondary analysis of a population-based cross-sectional study. Global Mental Health. 2018; 5. Available from https://doi.org/10.1017/gmh.2018.28.

4. WHO. Global status report on alcohol and health. Geneva, Switzerland. In World Health Organization (Vol. 122). 2014. Available from: https://doi.org//entity/substance abuse/pub lications/global_alcohol_report/en/index.h tml.

5. Rock B, Catherin N, Mathew T, Navshin S, Kurian H, Sherrin S, et al. Alcohol use and mental health among migrant workers. Indian Journal of Public Health Research and Development. 2016; 7(4): 169-173. Available from https://doi.org/10.5958/09765506.2016.00212.6.

6. Grzywacz JG, Quandt SA, Isom S, \& Arcury TA. Alcohol use among immigrant latino farmworkers in North Carolina.
American Journal of Industrial Medicine. 2007; 50(8): 617-625. Available from https://doi.org/10.1002/ajim.20482.

7. World Health Organization. Global status report on alcohol and health. Geneva: WHO. 2011.

8. Babor TF, Higgins-Biddle JC, Saunders JB, Monteiro MG. The alcohol use disorder identification test: guidelines for use in primary care, second edition. World Health Organization. 2001. Available from: https://apps.who.int/iris/bitstream/handle/1 0665/67205/WHO_MSD_MSB_01.6a.pdf

9. Region SA. Country profiles south-east asia region. World Health. 2004; 9: 1-33.

10. Blas E, Kurup AS, World Health Organization (eds). Equity, Social Determinants, and Public Health Programmes. World Health Organization: Geneva, Switzerland; 2010.

11. Fawehinmi TO, Ilomäki J, Voutilainen S \& Kauhanen J. Alcohol consumption and dietary patterns: The FinDrink study. PLoS ONE. 2012; 7(6). Available from: https://doi.org/10.1371/journal.pone.0038 607.

12. Méjean C, Traissac P, Eymard-Duvernay S, El Ati J, Delpeuch F, \& Maire B. Influence of socio-economic and lifestyle factors on overweight and nutrition-related diseases among Tunisian migrants versus non-migrant Tunisians and French. BMC Public Health. 2007; 7. Available from: https://doi.org/10.1186/1471-2458-7-265.

13. Nguyen LT, Rahman Z, Emerson MR, Nguyen $\mathrm{MH} \&$ Zabin LS. Cigarette smoking and drinking behavior of migrant adolescents and young adults in Hanoi, Vietnam. Journal of Adolescent Health. 2012; 50(3 SUPPL.). Available from: https://doi.org/10.1016/j.jadohealth.2011.1 2.004 .

14. Azagba S \& Sharaf MF. (2011). The effect of job stress on smoking and alcohol consumption. Health Economics Review. 2011; 1(1): 1-14. Available from: https://doi.org/10.1186/2191-1991-1-15.

15. Virtanen M, Jokela M, Nyberg ST, Madsen IEH, Lallukka T, Ahola K et al. Long working hours and alcohol use: Systematic review and meta-analysis of published studies and unpublished individual participant data. BMJ (Online). 2015; 350(January): 1-14. Available from: https://doi.org/10.1136/bmj.g7772. 